\title{
Proposta de um jogo sério e desplugado para o ensino de algoritmos
}

\section{Proposal of a serious and unplugged game for teaching algorithms}

\author{
Ederson Bastiani ${ }^{1}$ \\ Laura Majolo Roman ${ }^{2}$ \\ Victoria Botelho ${ }^{3}$
}

\begin{abstract}
Resumo: Algoritmos é considerada uma disciplina base em cursos de informática, porém a maioria dos alunos apresenta grandes dificuldades na disciplina, o que causa altos índices de reprovações e, consequentemente, evasão nos cursos de informática. Diante disso, os Jogos Sérios têm se apresentado como uma ferramenta de apoio no processo de ensinoaprendizagem dessa disciplina pois tratam-se de jogos que conciliam a educação com o entretenimento dos jogos. Neste trabalho, foi realizado um estudo sobre a disciplina de algoritmos, suas dificuldades e sobre os jogos sérios. Também foi aplicado um questionário à turma de algoritmos de um curso superior de Tecnologia em Sistemas para Internet de uma instituição pública de ensino para identificar suas dificuldades na matéria e foram analisados dados de aprovações e reprovações de turmas anteriores deste curso. Por último, foi feita a proposta de um jogo sério desplugado como ferramenta de apoio à aprendizagem de algoritmos, a fim de diminuir as dificuldades na matéria, desenvolver habilidades da área de computação, motivar alunos e despertar seu interesse pela área.
\end{abstract}

Palavras-chave: Programação, Jogos educacionais

\begin{abstract}
Algorithms are considered a basic discipline in computer science courses, however, most of the students present great difficulties in the discipline, which causes high rates of disapproval and, consequently, avoidance in computer courses. In view of this, the Serious Games have been presented as a support tool in the teaching-learning process of this discipline because they are games that reconcile education with the entertainment of games. In this work, a study was carried out on the discipline of algorithms, their difficulties and on serious games. A questionnaire was also applied to the algorithm class of an Internet Systems Technology superior course of a public educational institution to identify its difficulties in this area and analyzed data of approvals and disapprovals of previous classes of this course. Finally, a serious game was proposed as a tool to support the learning of algorithms, in order to reduce difficulties in the field, develop computer skills, motivate students and arouse their interest in the area.
\end{abstract}

Keywords: Programming, Educational games

\section{INTRODUÇÃO}

As disciplinas de Algoritmos geralmente são trabalhadas nos primeiros semestres dos cursos de informática, sendo componentes curriculares que abordam conteúdos e conceitos que serão utilizados em outras disciplinas no decorrer da trajetória acadêmica (DE LIMA

1 \{ederson.bastiani@iffarroupilha.edu.br\}

2 \{lauramajoloroman@gmail.com\}

$3 \quad$ \{victoriabotelho14@gmail.com

Rev. CCEI - URCAMP, V.24, n39 2019 (Submetido 18/12/2018; Aceito 06/07/2019)

DOI: https://doi.org/10.30945/ccei-v24i39.2741 
JUNIOR; VIEIRA; VIEIRA, 2015).

Apesar de sua importância, estas disciplinas, de forma geral, remetem a altos índices de reprovação e evasão. Dentre os motivos, De Lima Junior, Vieira e Vieira (2015) citam que Algoritmos é onde geralmente ocorre o primeiro contato dos alunos com ambientes que trabalham raciocínio lógico e programação e, nesse sentido, o reconhecimento dos procedimentos necessários para se chegar à solução de um problema, ou seja, identificar os dados, o resultado esperado e o que é preciso para resolver o problema, forma uma situação crítica encontrada pelos alunos.

Outros fatores como a falta de tempo e didática dos professores, por exemplo, provoca desmotivação nos alunos, os quais acabam reprovando e abandonando a disciplina e, posteriormente, o curso (JÚNIOR; RAPKIEWICZ, 2004).

Desta forma, torna-se relevante estudar ferramentas e meios que busquem identificar os motivos para essas dificuldades e engajar os alunos no processo de ensino-aprendizagem. Nesse sentido, os chamados jogos sérios podem ser utilizados como uma ferramenta de apoio para a aprendizagem de algoritmos.

Segundo Pessini et al (2014 apud Chen e Michael, 2005) os jogos sérios são jogos em que a educação é o objetivo principal e se utilizam da diversão e do envolvimentos dos jogadores para alcançar um objetivo específico quer seja entregar um mensage, ensinar uma lição ou prover uma experiência.

A partir disso, este trabalho apresenta a proposta de desenvolvimento de um jogo sério, do gênero Role Playing Game (RPG), o qual busca estimular a aprendizagem de algoritmos através da representação gráfica dos mesmos.

O restante deste artigo está estruturado como segue: as seções 2 e 3 apresentam, respectivamente, uma revisão bibliográfica sobre algoritmos e uma visão geral de jogos sérios. A seguir, na seção 4, é abordada a metodologia do estudo. Logo, na seção 5, são apresentados dados de aprovações e reprovações em algoritmos assim como alguns resultados da aplicação de um questionário. Em seguida, a proposta de um jogo sério desplugado é descrita na seção 6 e, por fim, a seção 7 traz as considerações desta pesquisa. 


\section{ALGORITMOS}

Um algoritmo pode ser definido, segundo Forbellone e Eberspacher (2005, p. 3), como “uma sequência de passos que visam atingir um objetivo bem definido”. Na medida em que torna-se necessário especificar uma sequência de passos, é necessário pensar em ordem, ou seja, pensar em uma solução algorítmica.

A representação de uma solução algorítmica pode ocorrer tanto através de forma gráfica, a partir da utilização de diagrama de blocos, quanto através de forma textual, a partir de uma linguagem programação ou pseudocódigo (MANZANO; OLIVEIRA, 2016) (XAVIER, 2014).

Segundo De Lima Junior, Vieira e Vieira (2015), em cursos da área da computação, as disciplinas de Algoritmos constituem eixo básico e essencial na formação dos alunos porém, estes componentes curriculares são considerados desafiadores, tanto para estudantes quanto para professores. Na visão do aluno, de acordo com Raabe e Silva (2005), algoritmos exige o desenvolvimento de estratégias de solução de problemas lógico-matemático, que para muitos são complexos, abstratos e distantes do cotidiano. Para os professores, a disciplina exige uma forte demanda de interação a fim de atender, acompanhar, mediar e avaliar os alunos. Os autores também ressaltam que muitas vezes as dificuldades de aprendizagem em algoritmos não são detectadas ou atendidas em tempo hábil, provocando assim um elevado número de reprovações e desistências.

Desse modo, torna-se interessante a proposta de ferramentas engajadoras para o ensino de algoritmos, que permitam com que os professores acompanhem e avaliem os alunos e facilitem o aprendizado dos mesmos através, por exemplo, de um jogo sério que utilize componentes gráficos e não linguagens de programação propriamente ditas, como frequentemente ocorre nestas disciplinas.

\section{JOGOS SÉRIOS}

Jogos educacionais, também denominados de jogos sérios, são especificamente projetados para ensinar as pessoas um determinado assunto, expandir conceitos, reforçar o 
desenvolvimento, exercitar e aprender uma habilidade ou buscar uma mudança de atitude enquanto jogam (BATTISTELLA, 2016 apud DEMPSEY; RASMUSSEN; LUCASSEN, 1996). É importante ressaltar que, segundo Savi e Dra (2008), jogos com fins educacionais precisam possuir objetivos pedagógicos claros e ser inseridos num contexto ou situação de ensino, baseados numa metodologia que oriente o processo de aprendizagem.

A tentativa e erro nos jogos, de maneira geral, não é mal-vista, uma vez que o aluno passa a ser atuante e tomador de decisões e, em jogos virtuais, é possível fazer várias tentativas até que o jogador alcance seu objetivo (MATTAR, 2010). Os jogos educacionais possuem esta mesma despreocupação, revertendo como erros são tradicionalmente vistos na sala de aula, além de poder inserir o aluno em um espaço e tempo significativos e pedagogicamente limitados que exploram situações que podem ser futuramente profissionais e corriqueiras (GLORIA et al, 2014).

No entanto, o desenvolvimento de jogos sérios pode ser um tanto quanto desafiador, afinal, é necessário que haja integração do jogo com os princípios de aprendizagem efetiva de forma a balancear a jogabilidade com o conteúdo de aprendizagem (DA ROCHA; BITTENCOURT; ISOTANI, 2015).

Contudo, como benefícios, tem-se a motivação dos alunos, uma vez que os jogos são capazes tanto de divertir como incentivar a aprendizagem por meio de ambientes mais dinâmicos e interativos, despertando o interesse de estudantes, uma vez que as metas e desafios que precisam ser vencidos nos jogos causam provocações nas pessoas, o que as deixam motivadas. (SAVI; DRA, 2008).

Assim, o uso de jogos educacionais é visto como uma possibilidade de reduzir dificuldades encontradas em disciplinas em geral e também na disciplina de Algoritmos uma vez que, segundo Rapkiewicz et al (2006), os jogos desafiam o aluno a tomar decisões, a explorar, pesquisar, permitem que desenvolvam o pensamento criativo e lógico, além do efeito motivador. Isso tudo contribui para o processo de ensino-aprendizagem.

\section{METODOLOGIA}

Para alcançar os objetivos propostos nesta pesquisa, a metodologia foi estruturada em 
cinco etapas descritas a seguir.

Primeiramente, foi realizado um levantamento das aprovações, reprovações e evasões referentes às últimas cinco turmas da disciplina de Algoritmos do curso de Tecnologia em Sistemas para Internet de uma instituição pública de ensino.

Na segunda etapa, foi realizada uma revisão bibliográfica sobre algoritmos e jogos sérios para obter uma maior compreensão do assunto da pesquisa, dos problemas encontrados e as possíveis soluções ou formas de diminuir tais problemas. A revisão bibliográfica também auxiliou na elaboração de um questionário, o qual foi aplicado para uma turma de algoritmos do curso superior de Sistemas para Internet de uma instituição pública de ensino.

A aplicação do questionário, terceiro passo da metodologia, teve como objetivo verificar o interesse e os pontos de dificuldades dos sujeitos da pesquisa (alunos). Além de permitir uma análise da situação da turma pelo docente, os resultados coletados serviram para a elaboração de uma proposta de jogo sério.

A partir destes resultados, foram realizadas análises quantitativa e qualitativa sobre o público discente (quarta etapa). Por fim, com base nos contextos estudados, o quinto passo desta pesquisa propôs um jogo sério e desplugado, ou seja, não digital, baseado em cartas/RPG e com foco na lógica dos problemas e não em uma linguagem de programação, o qual será descrito na seção 6.

\section{RESULTADOS PARCIAIS}

Esta seção apresenta a análise dos passos 1 e 3 da metodologia aplicada neste trabalho. A Figura 1 apresenta o levantamento de aprovações, reprovações e evasões das últimas 5 turmas de Algoritmos de um curso superior da área da Computação de uma instituição pública de ensino. 
Figura 1: Aprovações e reprovações em Algoritmos em um curso superior de uma instituição federal de ensino.

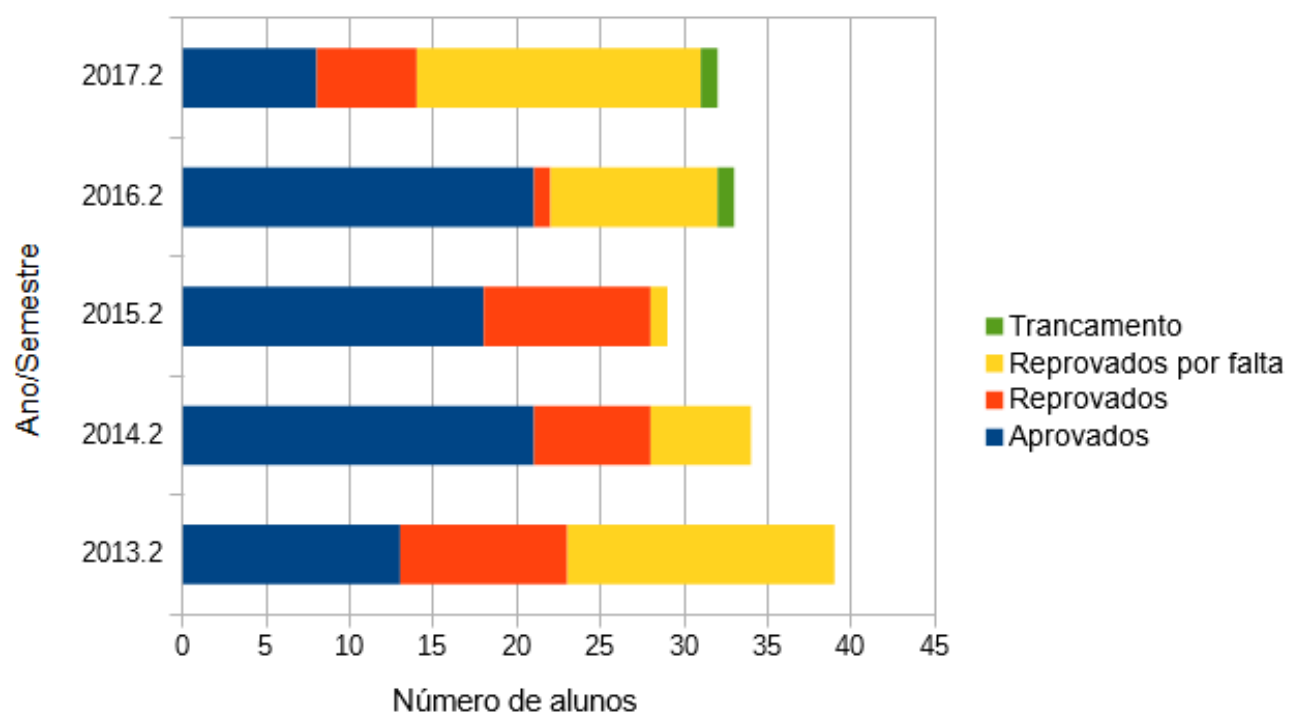

Fonte: Os autores, 2018.

Apesar de existirem três anos consecutivos com mais aprovações do que reprovações (2014-2016), é possível perceber que quase 50\% dos alunos, na média dos períodos analisados, reprovaram seja por notas ou por faltas. Estes dados vão ao encontro das respostas do questionário ${ }^{4}$ aplicado aos alunos da turma de 2018 dessa mesma instituição de ensino, onde $16,7 \%$ dos estudantes disseram encontrar muita dificuldade na disciplina e 38,9\% disseram se desmotivar em algum momento. Ressaltando que o questionário foi aplicado para uma turma de 18 alunos, sendo este o número de respostas obtidas.

Dentre as etapas da resolução de um algoritmo, 22,2\% dos discentes informaram que sua maior dificuldade está na identificação de entradas e saídas, o que pode estar relacionado com a baixa habilidade de raciocínio lógico e entendimento dos enunciados. Mesmo assim, $50 \%$ da turma afirmou que inicia codificando, ao invés de pensar e diagramar uma solução, o que pode causar confusões, retrabalho no momento da construção dos algoritmos e dificuldades nas resoluções.

Ainda, ao serem questionados se a utilização de recursos pedagógicos como atividades $4 \mathrm{O}$ questionário completo pode ser encontrado em: https://docs.google.com/forms/d/13MRFpCrGu$\underline{5 \mathrm{e} 4 \mathrm{VnPCgALeXJ76BFQaqS1OirfXFgZqFk/edit}}$ 
lúdicas seriam capazes de motivá-los, 94,4\% respondeu que sim.

Com o objetivo de diminuir as dificuldades em algoritmos, motivar os alunos e desenvolver habilidades da área da computação, propõe-se, neste trabalho, um jogo sério como ferramenta de apoio ao processo de ensino-aprendizagem de algoritmos.

\section{PROPOSTA DE UM JOGO SÉRIO E DESPLUGADO}

O jogo sério proposto neste trabalho, nomeado de DExHA, é um RPG (Role Playing Game) baseado em cartas, não digital (desplugado) e com foco no exercício da lógica de algoritmos. Para isso, a abordagem de resolução de algoritmos é realizada com base em diagramas de blocos, o que permite exercitar o raciocínio lógico dos alunos e desenvolver a prática de pensar e diagramar as soluções para os problemas algorítmicos.

O jogo é composto por dois grupos de até 4 jogadores cada, divididos entre desenvolvedores e hackers. A Figura 2 apresenta um exemplo de cada personagem do jogo.

Figura 2: Cartas dos desenvolvedores e hackers
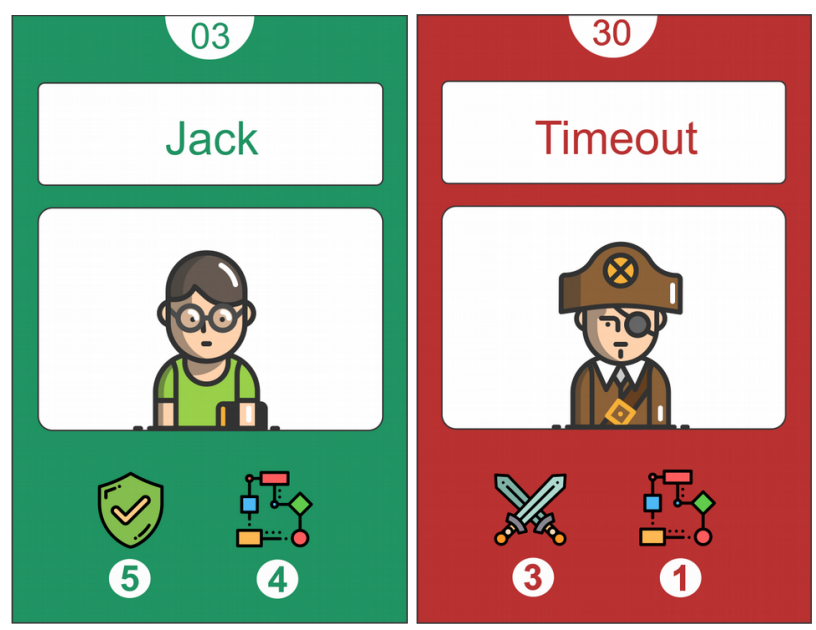

Fonte: O autor, 2018.

Ambos os grupos são incumbidos de percorrer um caminho em um tabuleiro e desenvolver uma quantidade de algoritmos proposta pelo professor para poder vencer o jogo. Além disso, como parte da dinâmica do jogo, a equipe de hackers deve impedir o avanço dos desenvolvedores, realizando ações de ataque. 
Sobre os algoritmos, o professor pode propor seus próprios problemas bem como utilizar o caderno de problemas que acompanha o jogo, o qual possui problemas de diversas áreas como matemática, física e química. Um exemplo de problema pode ser visto na Figura 3.

Figura 3: Problema proposto no caderno de problemas.

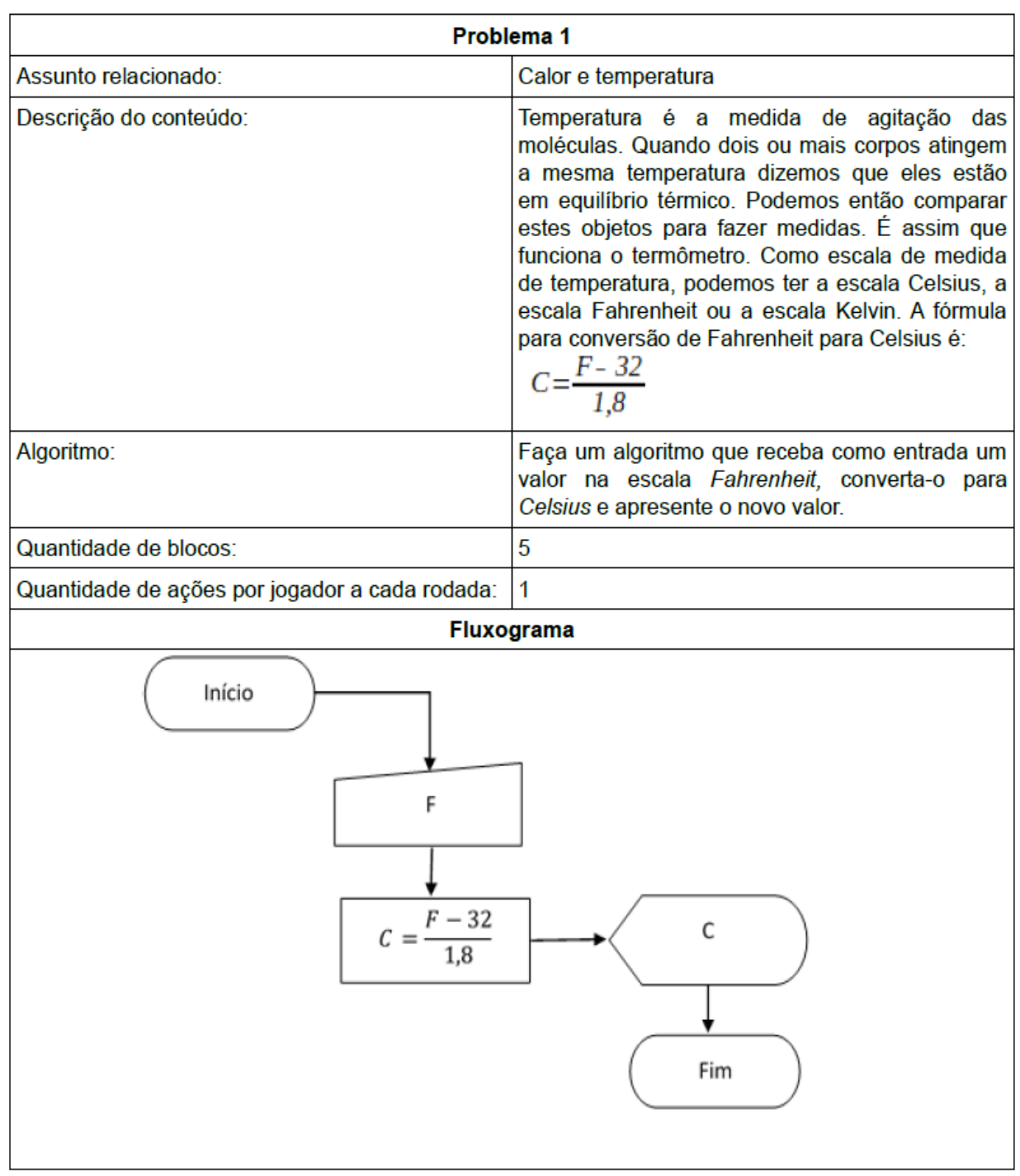

Fonte: O autor, 2018.

Além do enunciado, os problemas devem informar a quantidade de blocos que será utilizada e quantas ações podem ser executadas por cada jogador, por turno. Ainda, é necessário informar um diagrama de "gabarito” para o algoritmo, o qual pode ser utilizado tanto pelo professor quanto por um aluno moderador para conferir a solução apresentada pelos 
grupos.

Cada algoritmo deve estar relacionado com uma carta de algoritmo, a qual informa qual exercício do caderno de problemas deve ser resolvido, bem como o que a equipe ganha ou perde ao resolver, ou não, um problema, e o número máximo de rodadas para a execução do algoritmo.

Para o desenvolvimento dos algoritmos, durante uma partida, devem ser utilizadas as cartas de blocos, componentes que apresentam as figuras de um diagrama de blocos, como pode ser visualizado na Figura 4.

Figura 4: Cartas de blocos
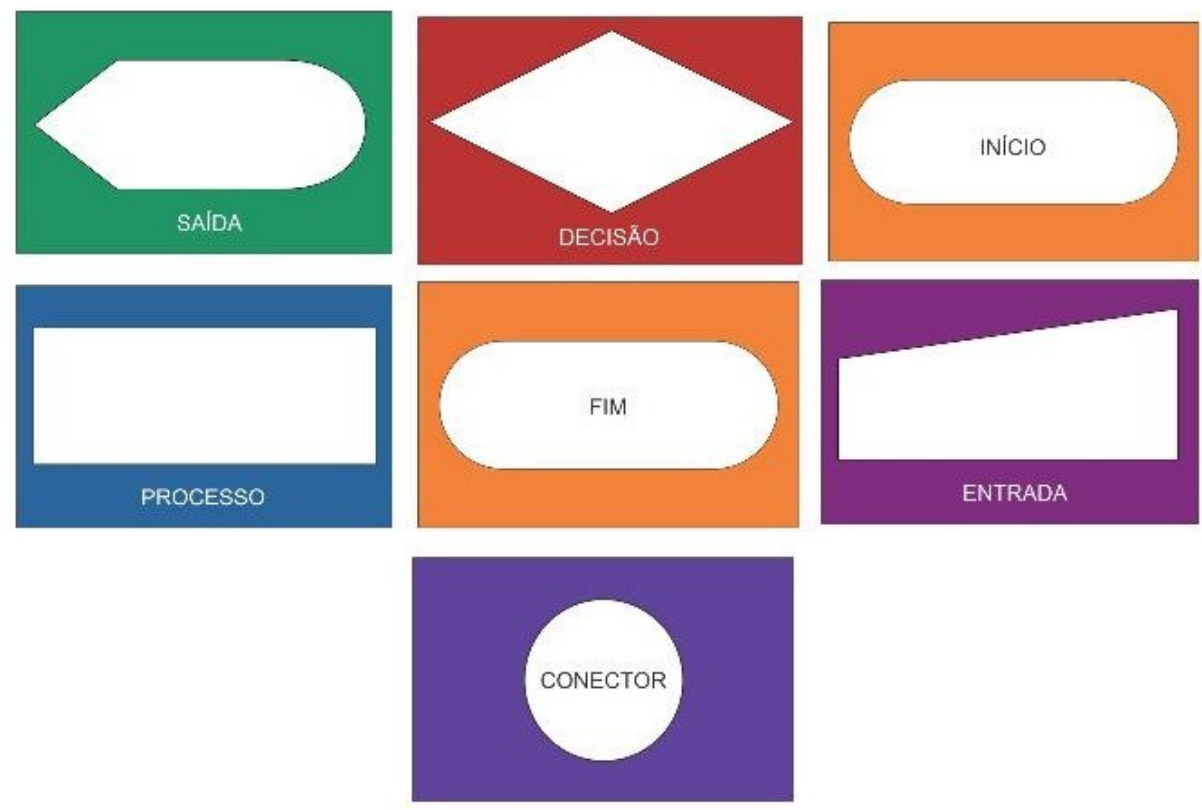

Fonte: O autor, 2018.

A maioria destas cartas possuem a figura do bloco em branco para que os alunos consigam escrever as instruções, por exemplo, valores de entrada. Já a escolha das cores permite aos alunos associarem padrões no decorrer de uma partida.

De forma a indicar o início, o fim e a quantidade de algoritmos que deverão ser resolvidos durante o jogo, o professor deve definir a trajetória que deve ser percorrida pelas equipes no tabuleiro do jogo, visualizado na Figura 5. Ressaltando que o professor pode distribuir aleatoriamente os algoritmos no tabuleiro ou, se preferir, pode verificar o grau de 
dificuldade dos problemas e, então, distribuí-los com base nesse aspecto.

Figura 5: Tabuleiro

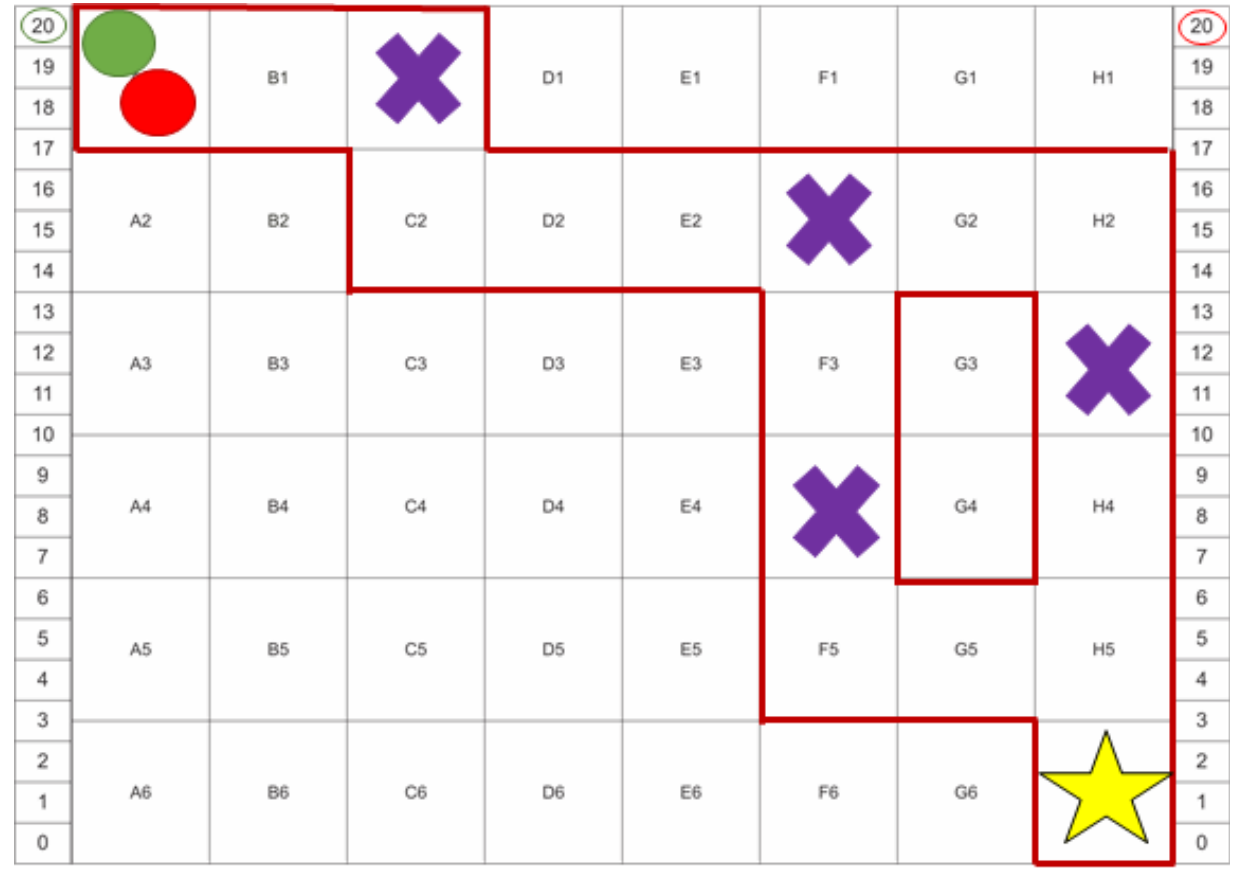

Fonte: O autor, 2018.

Na figura 5, é possível perceber o ponto de partida de ambas as equipes (célula A1), o caminho a ser percorrido, as posições onde existem algoritmos para serem resolvidos (células C1, F2, H3 e F4) e a posição de chegada (célula H6). Ainda, nos lados esquerdo e direito do tabuleiro existem os marcadores de moral, os quais possuem valores de 0 a 20 .

O avanço no tabuleiro se dá com base no trajeto definido pelo professor, no sorteio dos dados e na resolução dos algoritmos. Para avançar casas no tabuleiro, o jogador precisa de um valor mínimo de 1 no sorteio dos dados porém, quando o jogador se encontra em uma célula onde foi definido um algoritmo, o aluno deve resolvê-lo, caso contrário, permanece na célula até que o problema seja resolvido.

\subsection{MECÂNICA DO JOGO}

Esta seção tem como objetivo exemplificar a mecânica proposta para o DExHA, separada em duas etapas. A primeira é a configuração do ambiente do jogo, representado no 
diagrama da Figura 6.

Figura 6. Etapa de configuração do ambiente

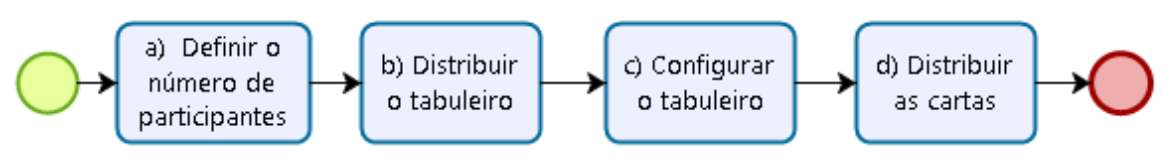

Fonte: O autor, 2018.

Conforme a Figura 6, o jogo começa com a definição do número de participantes pelo professor (passo $a$ ), sendo estes divididos entre as equipes de desenvolvedores e hackers. $\mathrm{O}$ segundo passo (b) trata da distribuição do tabuleiro e, em seguida, sua configuração, o que envolve a definição da quantidade de algoritmos a serem resolvidos, o caminho a ser percorrido pelas equipes no tabuleiro assim como os pontos de partida e chegada. Por último, o passo $d$ trata da distribuição das cartas para os jogadores encerrando, assim, a etapa de configuração do ambiente e iniciando a etapa de turnos dos jogadores.

Figura 7. Etapa de turnos dos jogadores

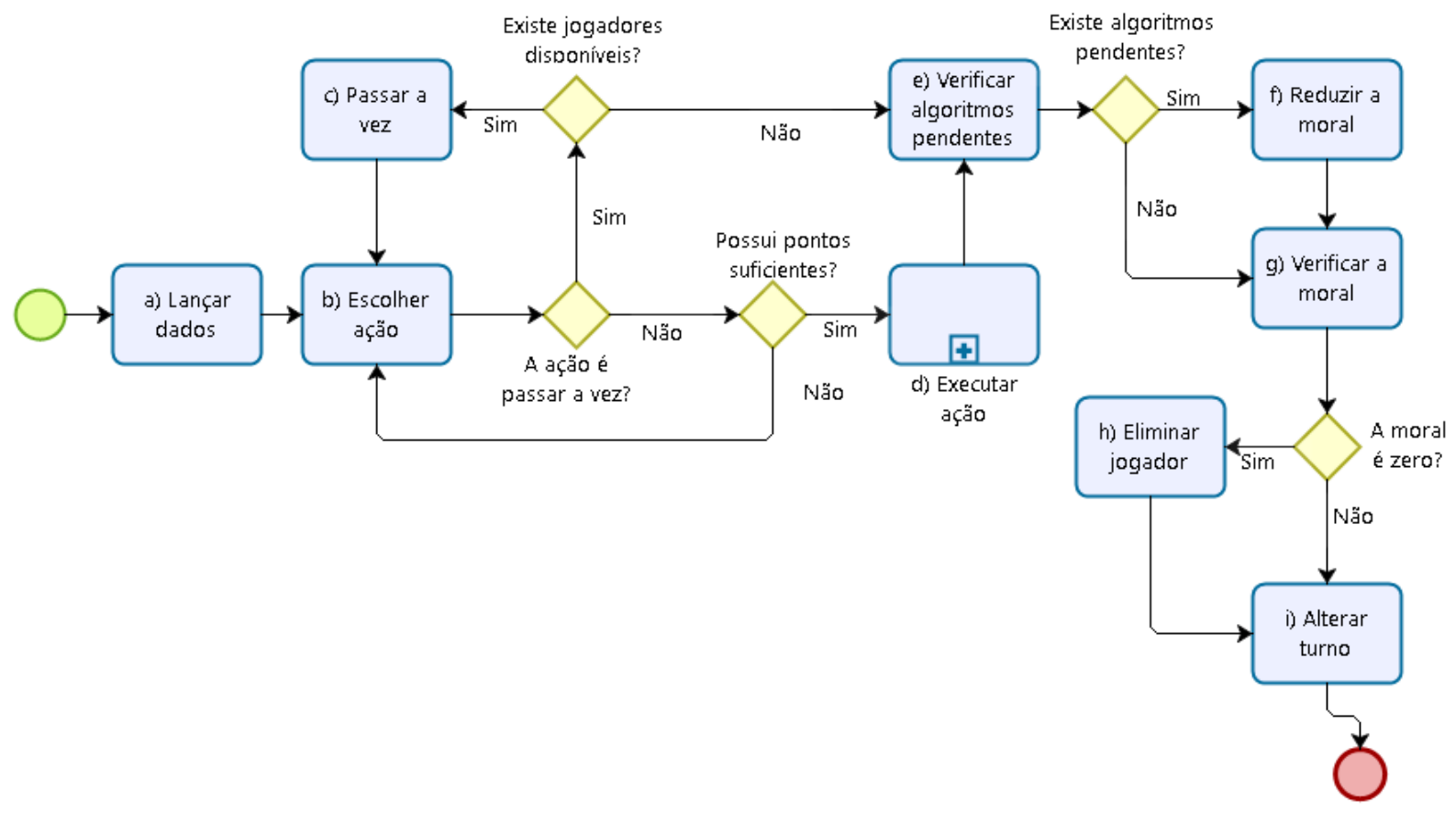

Fonte: O autor, 2018. 
Como mostra a Figura 7, a etapa de turnos dos jogadores segue o seguinte fluxo: inicia com o lançamento de dados pelos jogadores (passo a). Com isso, é possível escolher a ação ser tomada com relação ao jogo (b), chegando a uma condição: se o jogador não puder fazer uma ação com os valores obtidos no sorteio dos dados, então ele passa a vez e verifica se há outros jogadores do time disponíveis. Se sim, passa-se a vez de jogar para os outros participantes, voltando ao passo $b$.

Caso não seja preciso passar a vez, então o jogador verifica se possui pontos suficientes para executar uma ação. Se não tiver pontos suficientes, volta ao passo $b$, senão, executa uma ação $(d)$. As ações que o jogador pode executar podem ser a compra ou o uso de cartas de blocos, de ataque ou defesa. À medida que as equipes vão comprando cartas de blocos, vão construindo os algoritmos até completá-los. Durante esse processo, os hackers podem atacar os desenvolvedores por meio das cartas de ataque e os desenvolvedores, por sua vez, podem proteger-se com suas cartas de defesa.

O ataque dos hackers, pode ocorrer de duas maneiras: bloquear a ação de construção do algoritmo pelos desenvolvedores por 2 rodadas ou até que uma carta de defesa seja utilizada ou "roubar" uma carta de bloco do acervo dos desenvolvedores e utilizá-la ou colocá-la no final do monte de cartas de bloco. Já os desenvolvedores, a partir do uso de uma carta de defesa, podem impedir o ataque de duas maneiras: desbloqueando o bloqueio hacker com relação à construção do algoritmo, podendo assim, voltar a resolver o problema ou recuperar uma carta de bloco.

A partir do passo $d$, verifica-se se há algoritmos pendentes (e) sendo que, se houver algoritmos pendentes a resolver, diminui-se o ponto de moral, senão, verifica-se a moral $(g)$.

O passo g, que trata da verificação da moral, ocorre independente de haver ou não algoritmos pendentes. Assim, se a moral for zero, elimina-se o jogador de menor influência da equipe do jogo (passo $h$ ), senão, altera o turno da equipe (passo $i$ ), encerrando a etapa de turnos dos jogadores. 


\section{CONSIDERAÇÕES FINAIS}

Este estudo buscou entender e verificar soluções para suprir a dificuldade no processo de aprendizagem de algoritmos em cursos de informática, a fim de diminuir o número de reprovações e consequente evasão que os mesmos sofrem. Diante disso, os Jogos Sérios têm se apresentado como uma possível ferramenta de apoio ao processo de ensino-aprendizagem de algoritmos pois buscam conciliar a educação com o entretenimento, promovendo assim, a motivação, a interação entre jogadores, o desenvolvimento de habilidades exigidas pela disciplina como o raciocínio lógico além de despertar o interesse de alunos.

Após buscar referencial teórico, analisar dados de aprovações e reprovações em algoritmos e aplicar um questionário a uma turma de algoritmos do curso de Computação de uma instituição pública de ensino, foi proposto um Jogo Sério desplugado voltado para o exercício da lógica com base em diagramas de blocos.

Com base no resultado do questionário, percebe-se que o jogo poderia sanar algumas dificuldades e problemas observados nas respostas dos alunos como, por exemplo, a dificuldade no entendimento de enunciados e na identificação de entradas e saídas de um algoritmo, uma vez que, para realizar a montagem dos fluxogramas, o aluno precisa entender o enunciado e organizar e identificar os dados. Outros problemas observados como a baixa habilidade de raciocínio lógico, a codificação direta dos algoritmos (sem que os alunos pensem ou diagramem uma prévia solução) e a desmotivação também poderiam ser remediados ou amenizados pelo jogo proposto.

Enfim, as dificuldades apresentadas pelos alunos na disciplina de algoritmos de cursos de Computação precisam ser supracitadas e, para isso, é necessário um estudo e análise do que pode estar gerando essas dificuldades para então, buscar possíveis soluções que, ao menos, amenizem o problema.

\section{REFERÊNCIAS}

BATTISTELLA, PAULO EDUARDO. ENgAGED: Um processo de desenvolvimento de jogos para ensino em computação. Florianópolis. p. 23-401. 2016. Disponível em: $\leq$ https://bit.ly/2PPnwkW>. Acesso em: 07 junho 
2019.

DA ROCHA, RAFAELA VILELA; BITTENCOURT, IG IBERT; ISOTANI, SEIJI. Análise, Projeto, Desenvolvimento e Avaliação de Jogos Sérios e Afins: uma revisão de desafios e oportunidades. Anais do XXVI Simpósio Brasileiro de Informática na Educação (SBIE 2015). p. 692-701. 2015. Disponível em: <http://www.br-ie.org/pub/index.php/sbie/article/view/5342>. Acesso em: 26 maio 2018.

DE LIMA JUNIOR, JOSÉ AUGUSTO TEIXEIRA; VIEIRA, CARLOS EDUARDO COSTA; VIEIRA, PRISCILA DE PAULA. Dificuldades no processo de aprendizagem de Algoritmos: uma análise dos resultados na disciplina de AL1 do Curso de Sistemas de Informação da FAETERJ - Campus Paracambi. Cadernos $\begin{array}{lllllll}\text { UniFOA, } & \text { n. } & 27, & \text { p. } & 6-15, & 2015 . & \text { Disponível }\end{array}$ <http://revistas.unifoa.edu.br/index.php/cadernos/article/view/293/346>. Acesso em: 07 maio 2018.

FORBELLONE, ANDRÉ LUIZ VILLAR; EBERSPACHER, HENRI FREDERICO. Lógica de Programação: A construção de algoritmos e estruturas de dados. SP. p. 1-208. 2005. Disponível em: <https://bit.ly/2PTYKQL>. Acesso em: 29 maio 2018.

GLORIA, ALESSANDRO DE et al. Serious Games for education and training. ResearchGate. 2014. Disponível em: <https://bit.ly/2Q09UDg>. Acesso em: 22 novembro 2018.

JÚNIOR, JOSÉ CARLOS ROCHA PEREIRA; RAPKIEWICZ, CLEVI ELENA. O Processo de EnsinoAprendizagem de Fundamentos de Programação: Uma Visão Crítica da Pesquisa no Brasil. BDBComp. p. 1-7. 2004. Disponível em: <http://www.lbd.dcc.ufmg.br/colecoes/weirjes/2004/003.pdf>. Acesso em: 21 maio 2018.

MANZANO, JOSÉ AUGUSTO N. G.; OLIVEIRA, JAYR FIGUEIREDO DE. Algoritmos: lógica para desenvolvimento de programação de computadores. 28. ed. São Paulo: Érica/Saraiva. 2016. 336 p.

MATTAR, JOÃO. Games em educação: como nativos digitais aprendem. São Paulo: Pearson Prentice Hall, 2010.

PESSINI, Adriano et al. O uso de Jogos Sérios na Educação em Informática: Um Mapeamento Sistemático.

Nuevas Ideas en Informática Educativa TISE. p.537-541. 2014. Disponível em: $<$ http://www.tise.cl/volumen10/TISE2014/tise2014 submission 105.pdf> $>$. Acesso em: 08 junho 2019.

RAPKIEWICZ, CLEVI ELENA et al. Estratégias Pedagógicas no Ensino de Algoritmos e Programação Associados ao Uso de Jogos Educacionais. Novas Tecnologias na Educação V.4 N², p.1-10, Dezembro, 2006. Disponível em: <http://seer.ufrgs.br/index.php/renote/article/view/14284/8203>. Acesso em: 01 maio 2018.

RAABE, ANDRÉ LUÍS ALICE; SILVA, JÚLIA MARQUES CARVALHO DA. Um Ambiente para Atendimento às Dificuldades de Aprendizagem de Algoritmos. XXV Congresso da Sociedade Brasileira de Computação. p. 2326-2337. SC. 2005. Disponível em: <http://www.lbd.dcc.ufmg.br/colecoes/wei/2005/003.pdf>. Acesso em: 08 maio 2018

SAVI, RAFAEL; DRA, VANIA RIBAS ULBRICH. Jogos Digitais Educacionais: Benefícios e Desafios. Novas Tecnologias na Educação. V. $6 \mathrm{~N}^{\circ} \quad 2 . \quad$ p. $1-10.2008 . \quad$ Disponível em: <http://seer.ufrgs.br/renote/article/view/14405.\%20Acesso\%20em\%2017/11/2015>. Acesso em: 26 maio 2018.

XAVIER, GLEY FABIANO CARDOSO. Lógica de programação. São Paulo: Senac. 2014. 